\title{
Effects of the COVID-19 Pandemic on Eating and Meat Consumption Habits of Turkish Adults
}

\author{
Güliz Haskaraca ${ }^{1, a, *}$, Esra Bostanci ${ }^{2, b}$, Yusuf Arslan ${ }^{3, c}$ \\ ${ }^{1}$ Department of Food Engineering, Faculty of Engineering, Sakarya University, 54050 Sakarya, Turkey \\ ${ }^{2}$ Department of Food Engineering, Faculty of Engineering, Zonguldak Bülent Ecevit University, 67100 Zonguldak, Turkey \\ ${ }^{3}$ Business School, Sakarya University, 54187 Sakarya, Turkey \\ *Corresponding author \\ A R T I C L E I N F O A B S T R A C T \\ Research Article \\ Animal originated proteins have great importance in meeting the daily protein need in a healthy and \\ balanced diet due to their high protein content, amino acid pattern and good digestibility. Also, \\ when included in a diet, they play an important role in the protection of individuals' health and \\ improving the life quality with their vitamin and mineral content. The aim of this study is to \\ Received : 24/06/2020 \\ Accepted : 23/11/2020 \\ investigate the changes in meat and meat products consumption habits of people and whether they \\ are concerned about reaching meat and meat products during the COVID-19 pandemic. For that \\ purpose, a 24-question survey of 1000 people from several cities of Turkey was carried out. The \\ majority of the participants stated that their consumption of red meat $(77 \%)$, poultry meat $(81 \%)$ \\ and fish $(66 \%)$ did not change due to the COVID-19 pandemic, while $10 \%, 8 \%$, and $3 \%$ of the \\ Keywords: \\ Meat consumption \\ participants said their red meat, poultry meat and fish consumption increased, respectively. In \\ Dietary habits \\ COVID-19 \\ Pandemic \\ Food consumption habits \\ addition, $13 \%, 11 \%$, and $31 \%$ of the participants said there was a decrease in their red meat, poultry \\ meat and fish consumption, respectively. The major reason for the decrease in red and white meat \\ consumption was economic reasons, however, the reason for the decrease in consumption of fish \\ was difficulties in reaching. During the COVID-19 pandemic, until the date that the survey was \\ done, $12 \%$ of the participants had concerns about reaching meat and meat products. The main cause \\ of their concern was being unemployed or losing their job after the COVID-19 pandemic.
}

gyaldirak@sakarya.edu.tr (iD) https://orcid.org/0000-0002-4641-866X

usufarslan@sakarya.edu.tr (i) https://orcid.org/0000-0002-1873-7567

b@esra.bostanci@beun.edu.tr 1

(c) () () T) This work is licensed under Creative Commons Attribution 4.0 International License

\section{Introduction}

A new coronavirus (severe acute respiratory syndrome coronavirus 2 (SARS-CoV-2)) emerged in the Hubei province of China in the very late of 2019 (Huang et al., 2020). This virus spread rapidly all over the world in just a few months. On 11 February 2020, World Health Organization (WHO) announced a name for the new coronavirus disease: COVID-19 and on 12 March 2020, the COVID-19 was declared as a pandemic disease by WHO (WHO, 2020a). By 5 June 2020, there had been $6,515,796$ confirmed cases of COVID-19, including 387,298 deaths (WHO, 2020b) and the number of cases still continues increasing. According to these results $5.94 \%$ of confirmed cases have lost their lives. The case numbers and fatality rates are changing constantly in different countries, and all the countries are taking their own precautions such as ordering a curfew and taking hygienic measures. However, it is a sad reality that this pandemic will affect all the countries. Many parameters from countries' economies to the socio-psychological status of individuals will be affected by the COVID-19, but how much will this impact be? Many authorities and their communities are looking forward to the answer of this question. Regarding the food sector, Hailu (2020) reported that the COVID-19 pandemic is not only a public health issue, it is also an issue of food supply and added that there was a sharp increase in derived retail demand and a sharp drop in food service demand for processed food, at the onset of the pandemic in Canada.

Throughout the history of humanity, meat and meat products both manufactured from cattle, poultry or fish, have been the main dietary source of people. They play a major role in human nutrition with their high protein, vitamin and mineral content. Thus, eating meat has been recommended as an essential part of a healthy diet, and when included in a healthy diet, they contribute to individuals' healthy living. Although people have been eating meat for years, the emergence of some zoonotic or pandemic diseases can change individuals' meat 
consumption habits (Ishida, Ishikawa and Fukushige, 2010). When the COVID-19 first appeared, it was thought that people contracted the virus from seafood at Wuhan's Huanan Seafood Wholesale Market, where fish and wild animals are sold because the first cases had been to this market prior to their illness. Not surprisingly, both this situation and precautions such as curfews directly affected the food industry in regard to demand types and consumption types (Cöl and Günes, 2020, Lu et al., 2020, Sohrabi et al., 2020). For example, restaurants and fast food restaurants slowed down their activity, and a trend to prepare meals at home began.

In the current study, we aimed to determine how this pandemic affected the meat and meat consumption habits of people and to evaluate their concerns about reaching meat and meat products during the COVID-19 pandemic.

\section{Materials and Methods}

In the current study, a questionnaire study was administered in order to determine the effects of the COVID-19 pandemic on eating and meat consumption habits of people during the COVID-19 pandemic. To that end, an online survey was created by using Google forms and all the results were collected online. The survey was carried out between the $8^{\text {th }}$ and $14^{\text {th }}$ of May 2020 in Turkey, with the attendance of 1000 people. In total 24 different questions (including both multiple-choice questions and open-ended questions) were asked to the participants to determine the consumer profile, meat consumption habits, and the effects of the COVID-19 pandemic on their nutrition and meat consumption habits. Among the 24 questions, one question was specifically asked in order to analyze the concerns of participants about reaching meat and meat products during pandemic. The questions in the questionnaire are shown in Table 1. The first COVID-19 case happened on the $11^{\text {th }}$ of March 2020 in Turkey. The data were analyzed through descriptive statistics and chisquare analyses by using the IBM SPSS 20 statistic program (IBM Corp., 2011).

\section{Results and Discussion}

The demographic profile of the participants was given in figure 1 (a-e). When the demographic data of the surveyed participants were examined, it was observed that $28.6 \%$ of the participants were male, $71.4 \%$ were female, $60 \%$ of the participants were single and $40 \%$ were married. The majority of the participants were between the ages of 18 and 34 while only $3 \%$ of the participants were over the age of 55. In addition, among 1000 participants, 747 of them $(74.7 \%)$ have at least one university or higher education degree while $20 \%$ and $5 \%$ of them have a high school and primary school degree, respectively.

Figure 2 shows the answers to the question "How do you evaluate your socio-economic situation?" It was observed that most of the participants evaluate their socioeconomic status as neither good nor bad (mediocre) $(58.3 \%)$ while $36.3,2.2,2.4$ and $0.8 \%$ of the participants evaluated their status as good, very good, bad, and very bad, respectively.

As a result of the precautions against the pandemic, most of the manufacturing sector slowed down their production and operations, and most probably due to the decrease in demands and yield compression, some of them dismissed workers in order to survive. Although many governments took measures to prevent people from losing their jobs, at the onset of the pandemic job cuts became inevitable. According to the survey results, it was observed that $35.2 \%$ of the participants continued working during the pandemic while $19.2 \%$ of the participants lost their job and became unemployed.

Table 1. Questions of the questionnaire

1. What is your gender?

2. How old are you?

3. What is your marital status?

4. What is your level of education?

5. What is the size of the place where you live?

6. How do you evaluate your socio-economic status?

7. Have you been employed during the COVID-19 pandemic?

8. Have you worked from home or in your workplace during the COVID-19 pandemic?

9. What is the total number of people you live with during the COVID-19 pandemic?

10. Has the amount of food you eat changed during the COVID-19 pandemic?

11. Tick the option that best describes your eating habits during the COVID-19 pandemic.

12. Have you had concerns about reaching meat and meat products (red meat, poultry meat, fish) during the COVID-19 pandemic?

13. Do you consume red meat in your daily life?

14. How often did you consume red meat before the COVID-19 pandemic?

15. Has your red meat consumption changed during the COVID-19 pandemic?

16. If your consumption of red meat has decreased during the COVID-19 pandemic, what was the reason?

17. Do you consume white meat in your daily life?

18. How often did you consume white meat before the COVID-19 pandemic?

19. Has your white meat consumption changed during the COVID-19 pandemic?

20. If your consumption of white meat has decreased during the COVID-19 pandemic, what was the reason?

21. Do you consume fish in your daily life?

22. How often did you consume fish before the COVID-19 pandemic?

23. Has your fish consumption changed during the COVID-19 pandemic?

24. If your consumption of fish has decreased during the COVID-19 pandemic, what was the reason? 


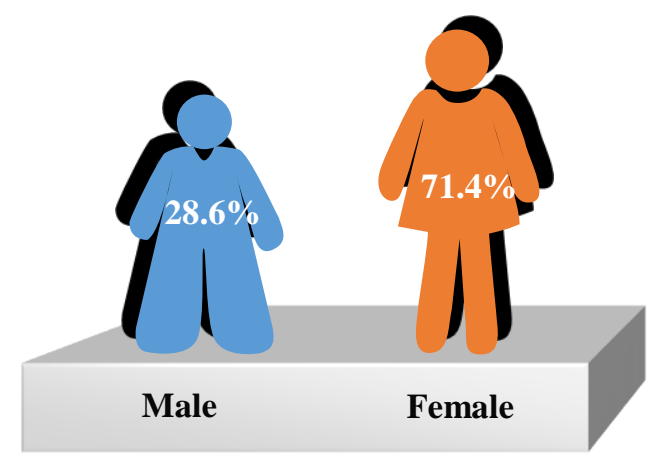

Figure 1a. Gender distribution of the participants

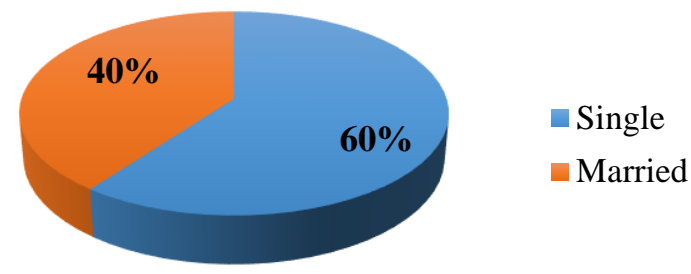

Figure 1b. Marital status of the participants

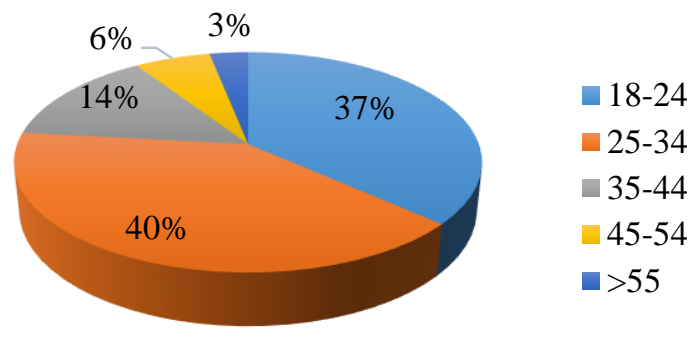

Figure 1c. Age distribution of the participants

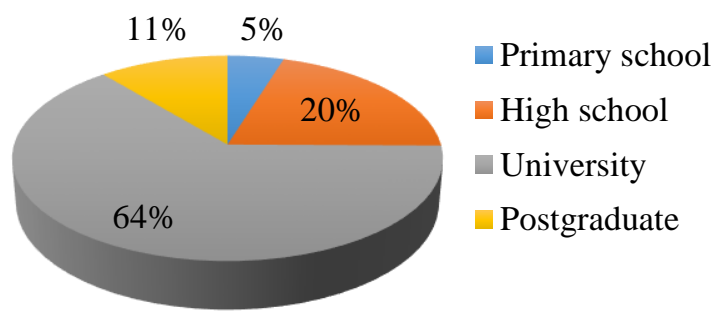

Figure 1d. Education level of the participants

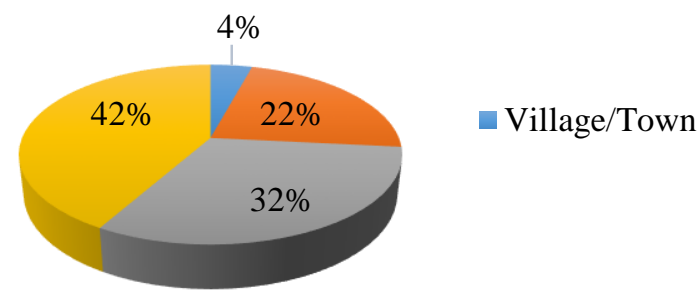

Figure 1e. The size of the area where participants live Figure 1. Demographic structure of participants
Figure 3 shows the changes in the amount of eating during the COVID-19 pandemic. Accordingly, it was observed that $53 \%$ of the participants did not change their eating habits during the COVID-19 period until the survey was done, but $35 \%$ of the participants started to eat more and $12 \%$ of the participants started to eat less. During the curfews and "stay home" calls, some of the people started to spend more time in their kitchens in order to pass the time, and tried to make homemade meals that they did not make before due to their intensive work schedule. Most probably because of making more foods at home, people ate more. On the other hand, $22 \%$ of the participants said that they paid more attention to healthy eating compared to the time before COVID-19 pandemic.

According to the results obtained via chi-square analyses, it was understood that the demographic profile of the participants is a significant factor in terms of the difference between the answers given to the question "Has the amount of food you eat changed during the COVID-19 outbreak?" There is a statistically significant difference between the gender of the participants and the changes in their eating habits in the COVID-19 period $(\chi 2=25.293$, $\mathrm{P}<0.001)$. According to these results, it can be said that, within the COVID-19 period, female participants have started eating significantly more than the male participants. In addition, there is a statistically significant difference between the age groups of the participants in terms of their eating habit changes in the COVID-19 period $(\chi 2=56.121$, $\mathrm{P}<0.001)$. According to Tamhane's T2 test results, the 18 24 age group is significantly different than the other groups (except the group 55\& above) and $45-54$ age group is significantly different from 25-34 \&35-44 age groups in terms of their eating habits change within the COVID-19 period ( $\mathrm{P}<0.05$ for all the comparisons). The highest changes have been observed in the age groups 18-24 and $45-54$ (mean dif=0.486, $\mathrm{P}<0.001$ ). However, there is no statistically significant difference between the educational levels of the participants and the changes in their eating habits during the COVID-19 pandemic $(\chi 2=11.853$, $\mathrm{P}=0.055>0.05)$. A statistically significant difference was found between the socio-economic levels of the participants when the changes in their eating habits in the COVID-19 period was observed $(\chi 2=19.499, \mathrm{P}=0.003$ $<0.05)$. According to Tamhane's T2 test results, the significant difference occurs between the groups which stated that their socio-economic statuses were "good" and "bad" (mean dif. $=-0.524, \mathrm{P}=0.045$ ) and also for the groups with "moderate" and "bad" socio-economic statuses (mean dif. $=-0.426, \mathrm{P}=0.029<0.05)$.

\section{Changes in Red Meat Consumption Habits}

While $9.3 \%$ of the participants reported that they did not consume red meat for various reasons, $90.7 \%$ of the participants said they consumed red meat in their daily life. Whereas $4.2 \%$ of the participants indicated that they consumed red meat at least once a day, $49.1 \%$ and $37.6 \%$ of the participants consumed red meat at least once or twice a week, respectively. On the other hand, $9.1 \%$ of the participants indicated that they consumed red meat once a month or once a year. 


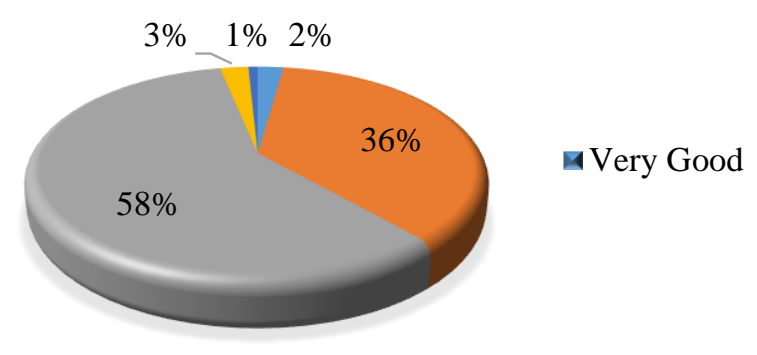

Figure 2. Participants' evaluation of their socio-economic structures

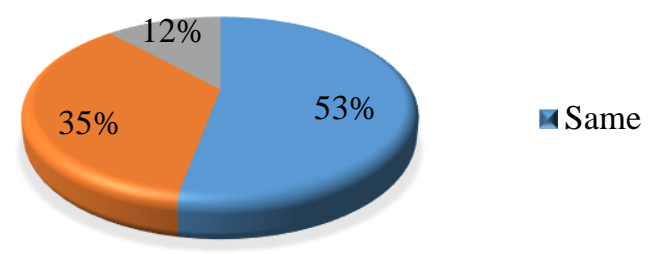

Figure 3. Changes in the participants' amount of eating during the COVID-19 pandemic

According to the results obtained via chi-square analyses, it was understood that the demographic profile of the participants is a significant factor in terms of the difference between the answers given to the question "Do you consume red meat in your daily life?" of the study. There is a statistically significant difference between the gender of the participants in terms of their red meat consumption in their daily life $(\chi 2=14.125, \mathrm{P}<0.001)$. According to this result, it can be said that, during the COVID-19 period, female participants have eaten significantly more red meat than the male participants. Also, there is a statistically significant difference between the age groups of the participants in terms of their red meat eating habits in their daily life $(\chi 2=17.891, \mathrm{P}=0.001$ $<0.05)$. According to Tamhane's T2 test results, the 45-54 age group is significantly different than the other groups $(\mathrm{P}<0.05)$ except for the group 55 and above in terms of red meat consumption levels. However, there is no statistically significant difference between the educational levels of the participants in terms of their red meat eating habits in their daily life $\left(\chi^{2}=7.323, \mathrm{P}=0.0570>0.05\right)$, the socioeconomic levels of the participants was found significantly influential on their red meat eating habits $(\chi 2=34.701$, $\mathrm{P}<0.001)$. According to Tamhane's T2 test results, the significant difference occurs between the groups who stated that their socio-economic statuses were good and moderate (mean dif. $=-0.053, \mathrm{P}=0.010<0.05$ ); and, for the groups with good and bad socio-economic statuses (mean dif. $=-0.294, \mathrm{P}=0.010<0.05)$.

Analyzing the changes in the participants' red meat consumption habits after the COVID-19 pandemic, $77.3 \%$ of the participants stated that their red meat consumption did not change due to the pandemic while $10 \%$ and $12.7 \%$ said that their red meat consumption increased and decreased, respectively. Half of $(50 \%)$ the participants whose red meat consumption reduced during the pandemic stated it was due to economic reasons, $18 \%$ said that they consumed less red meat due to difficulty in reaching it, and $21 \%$ said it was because they had concerns that red meat could be a source of the COVID-19 pandemic. In addition, $11 \%$ of the participants whose consumption of red meat decreased gave other reasons than the ones stated in the options for this question. Some of the answers given by the participants are as follows;

- I used to consume red meat in fast food restaurants before the COVID-19 pandemic, but my red meat consumption decreased due to the closure of fast food restaurants. (This answer was given mostly by students who returned to their hometown due to the closure of schools) (2\%).

- I used to consume red meat for lunch at work every day, but I do not consume red meat now because I am at home $(2 \%)$.

- My family prefers vegetable-based nutrition during the COVID-19 period (2\%).

- Because I shop online, I do not know how long it will take for the products that I buy to be delivered, so I am worried about the spoilage of the products that I buy in this process $(2 \%)$.

Comparing the demographic structure of the participants and the changes in their red meat consumption habits after the COVID-19 pandemic, it was observed that there is no statistically significant difference between the gender $(\chi 2=4.747, \mathrm{P}=0.093>0.05)$, age $(\chi 2=9.131$, $\mathrm{P}=0.331>0.05)$, educational level $\left(\chi^{2}=10.399\right.$, $\mathrm{P}=0.238>0.05)$ and socio-economic levels $(\chi 2=40.901$, $\mathrm{P}<0.001)$ of the participants in terms of the change in their red meat consumption during the COVID-19 period.

\section{Changes in White Meat Consumption Habits}

In regard to white meat consumption; $96 \%$ of the participants said that they consumed white meat in their daily life while $4 \%$ of the participants said they did not consume it. When it comes to how often they consume white meat, $18 \%$ of the participants consuming white meat said that they ate it rarely, $4 \%$ said that they consumed it every day, $40 \%$ said that they consumed it once a week, and $38 \%$ said that they consumed it at least twice a week. The results obtained via chi-square analyses showed that the demographic profile of the participants is not a significant factor in the difference between the answers given to the question "Do you consume white meat in your daily life?" No statistical differences was found between the gender $(\chi 2=0.108, P=0.871>0.05)$, age $(\chi 2=0.227$, $\mathrm{P}=0.994>0.05)$, educational levels $\left(\chi^{2}=2.234\right.$, $\mathrm{P}=0.693>0.05)$ and socio-economic status $(\chi 2=8.015$, $\mathrm{P}=0.091>0.05)$ of the participants and the change in their white meat consumption in their daily life.

While $81 \%$ of the participants stated that their consumption habits of white meat did not change due to the COVID-19 pandemic, $8 \%$ said their white meat consumption increased, and $11 \%$ said there was a decrease in their white meat consumption. The percentages of the participants with reduced white meat consumption due to economic reasons, not being able to reach it, being concerned that white meat could be a source of the COVID-19 and other reasons were 26\%, 27\%, 27\%, and 
$20 \%$ respectively. Some of the answers given by the participants choosing the other option are as follows;

- I do not know how long it will take for the products that I buy online to be delivered, so I am worried about the spoilage of the products that I buy until they arrive (1\%).

- I prefer to consume red meat and vegetables as I have returned to my hometown and I think it's healthier (4\%).

When the demographic structure of the participants and the changes in their white meat consumption habits after the COVID-19 pandemic were analyzed, it was observed that there is no statistically significant difference between the gender $(\chi 2=4.024, \mathrm{P}=0.134>0.05)$, age $(\chi 2=10.933$, $\mathrm{P}=0.206>0.05)$, and educational levels $(\chi 2=7.723$, $\mathrm{P}=0.259>0.05)$ of the participants and the change in their white meat consumption during the COVID-19 pandemic. However, a statistically significant difference was found between the socio-economic status $(\chi 2=14.995$, $\mathrm{P}=0.020<0.05)$ and the change in white meat consumption habits during the pandemic. $18 \%$ of those who evaluated their economic situation as bad or very bad stated that their white meat consumption decreased during the COVID-19 pandemic, while $75 \%$ of them reported that their white meat consumption did not change during the COVID-19 pandemic.

\section{Changes in Fish Consumption Habits}

It was observed that $88 \%$ of the participants consume fish in their daily life, while $12 \%$ do not. The percentages of the participants who consume fish once a week is $23 \%$, twice a week is $4 \%$, once a month is $56 \%$ and once a year is $17 \%$. According to the results of chi-square analyses, education level was found statistically influential on the fish consumption levels of participants in their daily life. Tamhane's T2 test results showed that a significant difference occurs between the group who has graduate education level and all the other educational level groups ( $\mathrm{P}<0.05$ for all of the comparisons). The highest difference was observed between the university graduated and primary school graduated groups (mean dif. $=0.225$, $\mathrm{P}=0.025<0.05)$. However, the effects of gender $(\chi 2=$ $0.108, \mathrm{P}=0.399>0.05)$, age $(\chi 2=7.800, \mathrm{P}=0.099>0.05)$ and socio-economic status $(\chi 2=7.279, \mathrm{P}=0.122>0.05)$ of the participants was not found statistically significant on their fish consumption habits.

It was determined that fish consumption of the participants, who did not consume fish in their daily life, was not affected by the COVID-19 pandemic. While $66 \%$ of the participants who consume fish stated that their fish consumption did not change due to the COVID-19 pandemic, $3 \%$ said that they ate more fish, and $31 \%$ reported a decrease in their fish consumption. The percentages of the participants with reduced fish consumption due to economic reasons, not being able to reach it, being concerned that fish could be a source of the COVID-19 and the end of the fish season due to the coming of summer were $10 \%, 63 \%, 14 \%$ and $13 \%$, respectively. Also, it was determined that there were no statistically differences between the demographic structure of the participants and the changes in their fish consumption habits after the COVID-19 pandemic in terms of gender $(\chi 2$ $=4,858 ; \mathrm{P}=0,088>0.05)$, age $(\chi 2=5,725 ; \mathrm{P}=0,678>0.05)$, educational level $(\chi 2=10,188 ; \mathrm{P}=0,117>0.05)$ and socioeconomic status $(\chi 2=3,305 \mathrm{P}=0,914>0,05)$.
A significant number of participants with reduced meat and meat products (red and white meat) consumption stated that they did shopping online during the curfews. However, because they did not know when it would be delivered and worried about the spoilage of the products they bought until they arrived, they did not order meat and meat products online. At this point, it is thought that a new tracking system which allows users to see when the orders were dispatched by the markets, where the transportation vehicle is at that specific moment and what temperature, and for how long, the products are exposed to until the delivery will be necessary.

Alpago and Oduncu Alpago (2020) defended that change and transformation process caused by the COVID19 pandemic will gain weight in the direction of digitalization and online transactions. On the other hand, a significant number of the participants $(63 \%)$ with reduced fish consumption during the COVID-19 pandemic said that they consumed less fish and fish products due to difficulty in reaching them. People who live in Turkey and consume fish can obtain fish and fish products not only from fish markets, fish restaurants and supermarkets, but they can also hunt. However, it is observed that individuals have difficulty in reaching fish and fish products due to the stay home calls and the risk that fish markets involve as social distancing would be hard to maintain in these places. At this point, it is thought that the sales of frozen fish and fish products on market shelves should be increased for people to be able to reach them more easily.

At the onset of the pandemic, there was a big obscurity and worry about how things would unfold. Most of the people were concerned about the future, and among the topics that they worried about most was accessing food because people should eat to survive and maintain their health. For this reason, in some countries, it was seen that some supermarkets were looted and people were stockpiling food in their homes. On the other hand, people can find vegetables, fruits or other food items more easily when compared to meat and meat products because they can be found in any market or supermarket in open air but meat and meat products require specific storage conditions and more attention in regard to food safety. In addition, as mentioned above people tended to do shopping online during the pandemic, so the storage and delivery requirements of meat and meat products may have affected their level of anxiety as it affected their consumption habits. For these reasons, in the current survey, participants were asked if they worried about reaching meat and meat products or not. Figure 4 shows the percentage of participants who were worried about reaching meat and meat products. It was observed that $88 \%$ of the participants did not worry about reaching meat and meat products while $12 \%$ of the participants did. After the first COVID-19 case was seen in Turkey, a curfew was implemented on the weekends and bank holidays after April 10th, 2020 (Anonymous, 2020). During these curfews most of the food producing companies did not cease production, and also big and small markets continued their sales activities in a controlled manner. In addition, authorities informed the public about food stocks. According to the survey data, it is concluded that the majority of the participants did not worry about reaching meat and meat products in Turkey most probably due to these controlled precautions. 


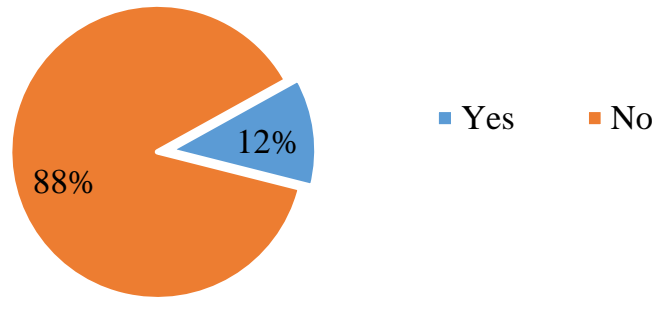

Figure 4. Worry about accessing meat and meat products

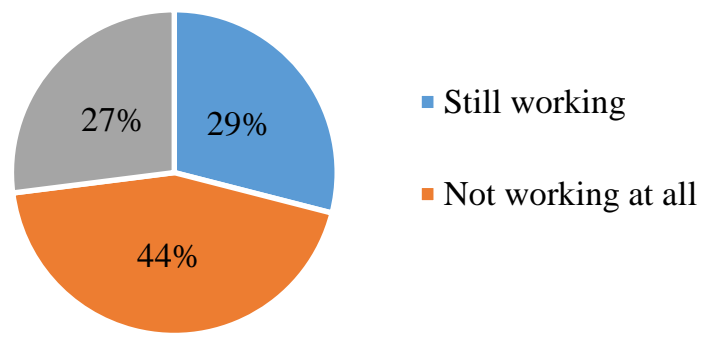

Figure 5a. Working status of worried participants

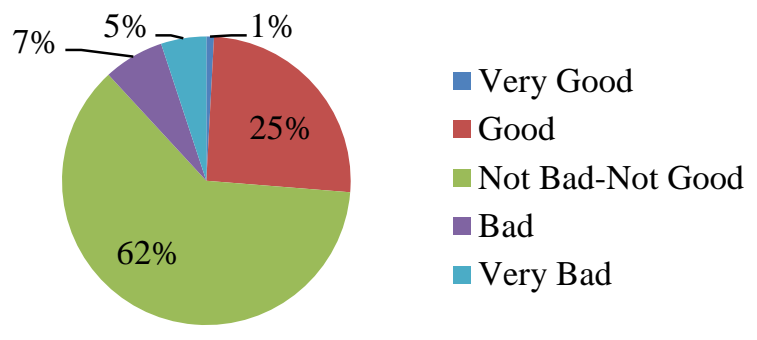

Figure 5b. Socio-economic status of the worried participants

Figure 5. Working status and socio-economic status of the worried participants

The effects of pandemics such as COVID-19 on the economic situation of countries have been investigated by researchers for years and it is stated that they have adverse effects on countries' economy (Bloom et al., 2005; Smith et al., 2009; Duffin, 2020; Fernandes, 2020). Researchers are still investigating the adverse effects of the COVID-19 pandemic on the economy of countries. Figure 5 (a-b) shows the working status and socio-economic status of the participants who worry about reaching meat and meat products. While $61.86 \%$ the participants who were worried about reaching meat and meat products evaluated their socio-economic status as neither good nor bad, $25.42 \%$ considered their socio-economic status was bad. In addition, $0.85 \%, 6.78 \%$ and $5.08 \%$ of the participants who worried about reaching meat and meat products evaluated their socio-economic status as very good, bad and very bad, respectively. According to the results of the present survey, $71 \%$ of the participants who are worried about reaching meat and meat products are those who did not work during the COVID-19 pandemic. Besides, 20\% of the participants who worked before the COVID-19 pandemic but stopped working for various reasons during the pandemic stated that they had concerns about reaching meat and meat products. It was determined that $10 \%$ of the participants who were working before and after the pandemic were concerned about reaching meat and meat products, and $12 \%$ of those who did not work before and during the pandemic worried about it. It was observed that participants whose economic status changed because of the COVID-19 pandemic were more worried about reaching meat and meat products. This concern seems to be quite understandable as meat and meat products are high-cost food items. On the other hand, when the level of concern according to age was examined, it was found that the majority of the people who had concerns about reaching meat and meat products were below the age of 34 while $19.35 \%$ of the participants who were over age 55 had concerns about reaching meat and meat products.

\section{Conclusion}

The COVID-19 pandemic is a major pandemic that has spread worldwide and affected the lives of many people all over the world. Since the announcement of the pandemic, many people and sectors have been affected by this disease. Also, we have seen that the pandemic affects not only the economy of people and countries, but also food and health sectors. On the one hand, at the beginning of the pandemic, many people from different countries looted the markets due to their concerns about reaching the food items. On the other hand, they tried to eat health food in order to boost their immune systems. In the direction of these behavioral changes the current study aimed to reveal the effects of COVID-19 pandemic on the meat consumption habits of people. Socio-economic status of the participants was found effective on the changes in their eating habits during the COVID-19 pandemic, especially for people who evaluate their socio-economic status as bad. In addition, $13 \%, 11 \%$, and $31 \%$ of the participants said there was a decrease in their red meat, poultry meat and fish consumption, respectively. The major reason for the decrease in red and white meat consumption was observed to be economic reasons, however, the reason for the decrease in consumption of fish was determined to be difficulties in reaching it. It was observed that a great majority of the participants did not worry about reaching meat and meat products. However, $12 \%$ of the participants had concerns about reaching meat and meat products due to being unemployed or losing their job after the COVID19. A significant number of participants with reduced red and white meat consumption said that they did shopping online because of the stay home calls during the COVID19 pandemic. At this point, monitoring of online shopping through new mobile applications is believed to be very important. Also, it was observed that the majority of the participants said that they had difficulty in reaching fish during the pandemic. In order to prevent this problem, it is believed that frozen fish sales should be increased for people to be able to reach them more easily during critical periods such as the second wave of COVID-19 or other possible pandemics. During these times, maintaining the healthy diet of the public is very important, which can be achieved by developing mobile tracking systems, which can facilitate the tracking of online market purchases, increasing the amount of packaged fish and fish products 
on market shelves and taking necessary steps to ensure economic stability.

\section{References}

Alpago H, Oduncu Alpago D. 2020. Socio-Economic Consequences of Coronavirus. IBAD Journal of Social Sciences, 8; 99-114. doi: 10.21733/ibad.716444

Anonymous. 2020. Official Website of The Presidential Republic of Turkey/Türkiye Cumhuriyeti Cumhurbaşkanlığ resmi WEB sitesi. Available from: https://www.tccb.gov.tr/ receptayyiperdogan/konusmalar/ [Accessed 26 May 2020]

Bloom E, Vincent de W, Mary Jane Carangal-San J. 2005. Potential Economic Impact of an Avian Flu Pandemic on Asia. Asian Development Bank, ERD Policy Brief, 42; 1-14. ISSN: 1655-5260 https://think-asia.org/handle/11540/2165

Cöl M, Günes G. 2020. COVID-19 Salgınına Genel Bir Bakıș. In: Memikoğlu O, Genç V (editors). COVID-19. Ankara, Turkey: Ankara University Press. pp:1-8. ISBN: 978-605136-477-3 (online).

Duffin E. 2020. Impact of the coronavirus pandemic on the global economy - Statistics \& Facts. Coronavirus: Impact on The Global Economy, Statistica, 138p.

Fernandes N. 2020. Economic Effects of Coronavirus Outbreak (COVID-19) on the World Economy. Available from: SSRN: https://ssrn.com/abstract=3557504 or http://dx.doi.or $\mathrm{g} / 10.2139 / \mathrm{ssrn} .3557504$

Hailu G. 2020. Economic thoughts on COVID-19 for Canadian food processors. Canadian Journal of Agricultural Economics. Special Issue Article, pp; 1-7. doi: https://doi.org/10.1111/cjag.12241

IBM Corp. (2011). IBM SPSS Statistics for Windows, Version 20.0. Armonk, NY: IBM Corp.

Ishida T, Ishikawa N, Fukushige M. 2010. Impact of BSE and bird flu on consumers' meat demand in Japan. Applied Economics, 42(1);49-56. doi: 10.1080/00036840701564392
Huang C, Wang Y, Li W, Ren L, Zhao J, Hu Y, Zhang L, Fan G, Xu J, Gu X, Cheng Z, Yu T, Xia J, Wei Y, Wu W, Xie X, Yin W, Li H, Liu M, Xiao Y, Gao H, Guo L, Xie J, Wang G, Jiang R, Gao Z, Jin Q, Wang J, Cao B. 2020. Clinical features of patients infected with 2019 novel coronavirus in Wuhan, China. Lancet, 395; 497-506. doi: https://doi.org/ 10.1016/S0140-6736(20)30183-5

Lu H, Stratton C W, Tang Y W. 2020. Outbreak of pneumonia of unknown etiology in Wuhan, China: The mystery and the miracle. Journal of Medical Virology, 92; 401-402. doi: https://doi.org/10.1002/jmv.25678

Smith R D, Keogh-Brown M R, Barnett T, Tait J. 2009. The economy-wide impact of pandemic influenza on the UK: a computable general equilibrium modelling experiment. British Medical Journal, doi: https://doi.org/ 10.1136/bmj.b4571

Sohrabi C, Alsafi Z, O'Neill N, Khan M, Kerwan A, Al-Jabir A, Iosifidis C, Aghad R. 2020. World Health Organization declares global emergency: A review of the 2019 novel coronavirus (COVID-19). International Journal of Surgery, 76;71-76. doi: https://doi.org/10.1016/j.ijsu.2020.02.034

WHO, 2020a. World Health Organization, WHO DirectorGeneral's Remarks at the Media Briefing on 2019-nCoV on 11 February 2020, Available from: https://www.who.int/ $\mathrm{dg} /$ speeches/detail/who-director-general-s-remarks-at-themedia-briefing-on-2019-ncov-on-11-february-2020 [Accessed 30 May 2020]

WHO, 2020b. World Health Organization, WHO Coronavirus Disease (COVID-19) Dashboard. Available from: https://covid19. who.int/?gclid=CjwKCAjw2uf2BRBpEiwA 31VZjyljy8tcaGwkdWBrzieRKsTREhtA4m7NzB_lmbYZE upALxBAn3Y9RxoCTrMQAvD_BwE [Accessed 5 June 2020] 